\title{
Load Aggregator Purchase Optimization Strategy Considering Renewable Energy Quota
}

\author{
$\operatorname{Li~Tao~}^{1,2}$, Jian Liu ${ }^{1,2}$, Jianye Zou ${ }^{1,2}$, Lin Zhang ${ }^{1,2^{*}}$ \\ ${ }^{1}$ Nari Group Corporation/State Grid Electric Power Research Institute, Nanjing, 210003, China \\ ${ }^{2}$ Beijing Kedong Electric Power Control System Co., Ltd. Beijing, 100194, China
}

\begin{abstract}
The introduction of the renewable energy quota system has an impact on the benefits of all market players in the electricity market. This paper aimed at the decision making of load aggregators' electricity purchase under the assessment of renewable energy quota. Firstly, the market subject, assessment method and strategy of renewable energy quota system were analyzed effectively. Then the scenario of electricity purchasing faced by load aggregators was described and the optimal decision-making model of electricity purchasing by load aggregators considering renewable energy quota was proposed. At last, the model proposed in this paper was verified by relevant examples, and the results show that the optimal purchasing strategy of load aggregator proposed in this paper had obvious economy.
\end{abstract}

\section{Introduction}

A load aggregator is a business organization that serves users to participate in the electricity market. It changes the overall load situation based on effective management. The load aggregator acts as an intermediary between users and the power grid, and participates in electricity market transactions by integrating user resources ${ }^{[1]}$.

Aiming at the analysis of the impact of renewable energy power consumption responsibility weights on the electricity market trading system, the literature ${ }^{[2-4]}$ introduced a design mechanism for green certificate trading and renewable energy quota system from the perspective of the macro electricity market mechanism and system. Aiming at the analysis of the impact of the renewable energy quota system on the main trading entities in the electricity market, Reference ${ }^{[5-7]}$ studied how electricity sales companies allocate power purchases in multiple markets such as forward, spot, and options, and complete assessment requirements. The certificate completes the re-assessment requirements for renewable consumption responsibility. In the existing literature, only the renewable energy consumption responsibility weight is used as a constraint condition of the model. The lack of a clear and feasible scheme for the consumption responsibility weight is not conducive to the implementation of market entities.

This paper studies the monthly power purchase strategy of load aggregators considering the weight of renewable energy consumption responsibility. Firstly, this paper analyzes the effect of renewable energy quotas on the power purchase mechanism of load agglomeration merchants, and then proposes a monthly power purchase strategy for load aggregators. Based on the power purchase strategy, a rolling optimization model for monthly power purchase decisions at the beginning of the year and power purchase decisions for the year is constructed. An example is given, and the example shows that the model can improve the economics of electricity purchase by load aggregators.

\section{Analysis of the impact mechanism of renewable energy consumption responsibility policy on market players}

On May 15, 2019, the National Development and Reform Commission issued several documents on "establishing and improving a renewable energy power consumption guarantee mechanism" after several comments. The document established the principle of joint responsibility for power consumption among power sales companies and power users. According to the document, the annual consumption of the load aggregator corresponds to its annual power consumption.

At present, in China's renewable energy assessment mechanism provide two remedies for some market entities that have not completed the corresponding quota indicators:

(1) Organize annual quota transactions, and market entities that have not completed quota indicators purchase corresponding quotas from market entities that have over-performed quota tasks; (2) Organize annual green permit transactions. After this transaction, you can purchase Certificate method to make up for the remaining quota.

As the current quota market system in China has not yet been fully established, the excessive price fluctuations in the green certificate market are accompanied by relatively large market price risks.

\footnotetext{
*Corresponding author: linlinhaoyou@163.com
} 
Therefore, for market players, purchasing renewable energy to meet quota quotas can reduce risks as much as possible when quota quotas are fulfilled, which is the most suitable way to complete quotas in the current scenario. Therefore, this paper studies the purchase of renewable energy to complete the renewable energy consumption obligation weight.

\section{Analysis of load aggregation commercial electricity purchase scenario}

\subsection{Analysis of Factors Affecting Purchase of Electricity by Load Aggregation}

As a special form of large users, load aggregators can purchase electricity through the wholesale electricity market to save electricity purchase costs and ensure stable power supply. At the same time, the load aggregator needs to be subject to quota assessment. How to complete the power quota standard while ensuring the power supply and demand is an important factor that load aggregators need to consider in the future power market. The power purchase scenario of the load aggregator is shown in Figure 1.

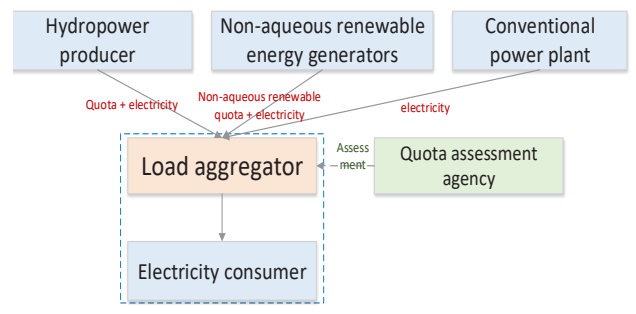

Fig. 1. Load aggregation business

On the one hand, the load aggregator purchases electricity from the wholesale electricity market and supplies it to electricity consumers, and on the other hand accepts the assessment by the quota assessment agency. Therefore, when making power purchase decisions, power resources from different sources should be purchased to complete the quota assessment task while ensuring energy supply. Quota assessment is carried out on an annual basis, and electricity purchases can be made in a variety of ways, including the medium and long-term market, the day-ahead market, and the real-time market. This article designs a power purchase plan on a monthly basis, considering that the monthly power forecast results are broken down into short-term There is no large error in the load change. The setting of monthly power purchase decisions not only ensures the rationality of power purchase decisions, but also facilitates timely adjustments in response to unexpected situations.

Based on the above analysis, load aggregators need to consider the following factors when making power purchase decisions.

(1) Meet the needs of power consumers.

(2) Satisfy the requirements for the weight of renewable energy consumption obligations.
(3) Market conditions.

(4) The profit of the load aggregator.

\subsection{Load Aggregation Commercial Purchasing Strategy}

This article studies the scenario where the load aggregator breaks down and implements renewable energy quotas and its monthly power purchase strategy during the year. The idea is to prioritize the purchase of clean power to meet quota assessment indicators in the monthly power purchase decision, and then purchase conventional power. The sum of the two is the total monthly power purchase cost. The process is as follows:

(1) Determine the total amount of electricity purchased in each month based on the historical monthly load of the aggregated users.

(2) Based on the annual quota assessment goals of the load aggregator, the weights of consumption responsibilities required to be completed each month are decomposed.

(3) The difference between the total amount of electricity purchased in each month and the quota to be completed in each month is the conventional electricity purchase.

(4) Combine the monthly electricity purchase cost of the quota and the monthly free purchase to get the total monthly electricity purchase cost.

(5) Summarize the total monthly power purchase cost. According to the total number of months, models with the minimum total purchase cost at the beginning of the year and the minimum total purchase cost during the year as the objective functions can be constructed.

(6) Based on the monthly clean energy prices and conventional electricity prices, solve the model to get the best monthly consumption responsibility index of the load aggregator.

\section{Load Aggregation Merchant Electricity Purchase Decision Optimization Model}

\subsection{Monthly power purchase decision at the beginning of the year}

When the load aggregator makes optimization decisions, the following factors need to be considered:

1) the needs of all load users should be met; 2) the quota index should be met, including the non-aqueous renewable consumption responsibility weight index and renewable energy Indicator of the weight of responsibility; 3) Hydropower and non-aqueous renewable energy power will not exceed its tradable power; 4) Minimize the cost of power purchases when three conditions are met Therefore, the following power purchase decision model can be obtained: 


$$
\begin{aligned}
& \min \sum_{i=1}^{12} Q_{i} q_{i}+\sum_{i=1}^{12} G_{i} g_{i}+\sum_{i=1}^{12} R_{i} r_{i} \\
& \text { s.t. }\left\{\begin{array}{l}
-\sum_{i=1}^{12} Q_{i} \leq-P_{q} \sum_{i=1}^{12} N_{i} \\
-\sum_{i=1}^{12} G_{i}-\sum_{i=1}^{12} Q_{i} \leq-P_{g} \sum_{i=1}^{12} N_{i} \\
Q_{i} \leq W_{i}, i=1,2, \cdots, 12 \\
G_{i} \leq E_{i}, i=1,2, \cdots, 12 \\
Q_{i} \geq 0, i=1,2, \cdots, 12 \\
G_{i} \geq 0, i=1,2, \cdots, 12
\end{array}\right.
\end{aligned}
$$

Among them, $\mathrm{R}_{\mathrm{i}}=\mathrm{N}_{\mathrm{i}}-\mathrm{Q}_{\mathrm{i}}-\mathrm{G}_{\mathrm{i}}$ represents the purchase of non-renewable energy electricity in the $\mathrm{i}$ month; $\mathrm{Q}_{\mathrm{i}}$ is the amount of non-aqueous renewable energy purchased in the ith month; $G_{i}$ is the hydropower purchase amount in the ith month; $\mathrm{N}_{\mathrm{i}}$ is the total amount of electricity purchased in the ith month; $\mathrm{W}_{\mathrm{i}}$ is the amount of nonaqueous renewable energy available for sale on the market in the ith month; $\mathrm{E}_{\mathrm{i}}$ is the saleable hydroelectric power in the ith month; $q_{i}$ is the average electricity price of non-aqueous renewable energy in the ith month on the electricity sales market; $g_{i}$ is the average price of hydropower in the ith month of the electricity sales market; $r_{i}$ is the average price of other electricity in the ith month in the electricity sales market; $\mathrm{P}_{\mathrm{q}}$ is the nonaqueous renewable energy quota ratio; $\mathrm{P}_{\mathrm{g}}$ is the proportion of renewable energy quota.

\subsection{Rolling optimization of power purchase decisions within the year}

During the year, a rolling optimization model for power purchase decisions during the year is constructed. The optimization method is to perform rolling optimization of future monthly power purchase decisions when the transaction has been completed. Its optimization model is shown in formula (2).

$$
\begin{aligned}
& \min \sum_{i=1}^{12} Q_{i} q_{i}+\sum_{i=1}^{12} G_{i} g_{i}+\sum_{i=1}^{12} R_{i} r_{i} \\
& \text { s.t. }\left\{\begin{array}{l}
-\sum_{i=1}^{12} Q_{i} \leq-P_{q} \sum_{i=1}^{12} N_{i} \\
-\sum_{i=1}^{12} G_{i}-\sum_{i=1}^{12} Q_{i} \leq-P_{g} \sum_{i=1}^{12} N_{i} \\
Q_{i} \leq W_{i}, i=1,2, \cdots, 12 \\
G_{i} \leq E_{i}, i=1,2, \cdots, 12 \\
Q_{i} \geq 0, i=1,2, \cdots, 12 \\
G_{i} \geq 0, i=1,2, \cdots, 12 \\
Q_{j}=Q_{n} \\
G_{j}=G_{n}
\end{array}\right.
\end{aligned}
$$

Where $\mathrm{a}$ and $\mathrm{b}$ are the past months of the year, and the other parameters are the same as in formula (1).

\subsection{Optimize decision results}

The optimization results of the above two optimization models are monthly hydropower and non-aqueous renewable energy power purchase schemes. This scheme can make load aggregators achieve the minimum annual power purchase cost under the background of the renewable energy quota system. The monthly power purchase plan at the beginning of the year is based on past power purchase experience and forecast results of future power market conditions, combined with year-end quota assessment requirements, to make the optimal power purchase decision plan for each month in the next year; rolling optimization of power purchase decisions during the year Fully considering the actual situation and forecast difference during the year, it is necessary to make timely adjustments to the power purchase plan during the year, so that the load aggregator can realize the monthly optimal power purchase decision under the current scenario.

\section{Example analysis}

\subsection{Optimal power purchase decision at the beginning of the year}

Based on the model used in Section 4.1, select the corresponding data of a certain load aggregator A's power purchase for a case analysis. According to the assessment requirements, A load aggregators need to complete $80 \%$ of renewable energy quotas and $3.5 \%$ of non-aqueous renewable energy quotas.

Based on the historical electricity consumption situation, the total monthly electricity purchase amount of A load aggregator in that year is obtained:

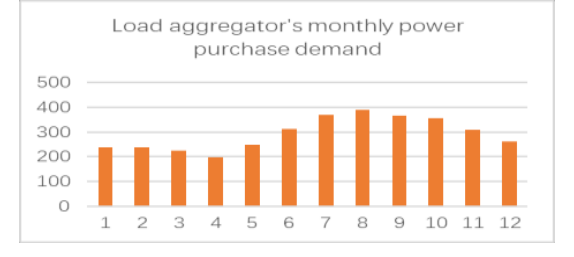

Fig. 2. Monthly electricity purchase demand of load aggregators

Based on historical market transactions, electricity prices for each month of the year are predicted:

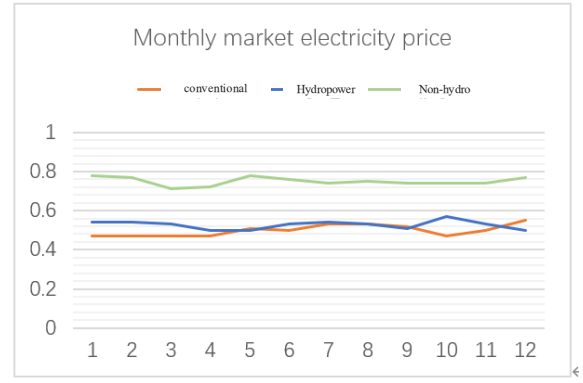

Fig. 3. Monthly electricity price of the electricity market

Set market electricity and non-aqueous renewable electricity electricity limits: 


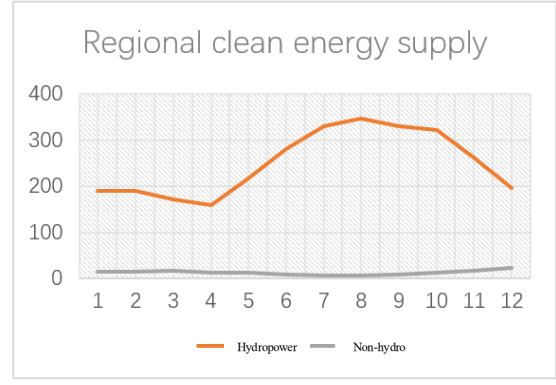

Fig. 4. Supply of clean energy in the region

Substituting relevant data into the model can get the annual optimal power purchase decision plan, and it is shown in Figure 4 to show its changing trend more clearly.

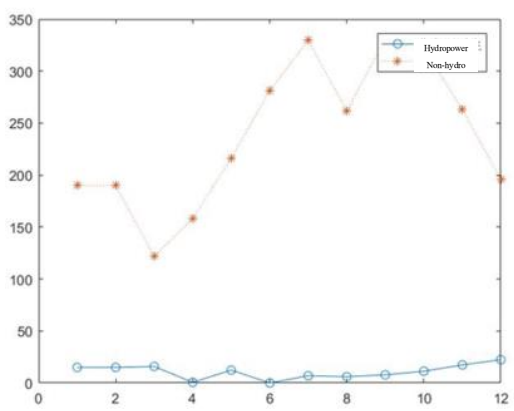

Fig. 5. Results of monthly power purchase decisions at the beginning of the month

In this case, it can be calculated that the total cost of minimizing electricity purchase in the final year is 1.928 billion yuan.

\subsection{Optimization of power purchase decisions within the year}

It is assumed that due to various factors of the market and load aggregators, the trading volume in the first six months is assumed to have occurred, as shown Fig. 6.

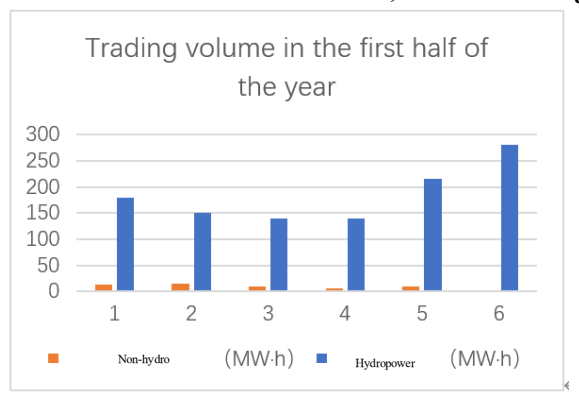

Fig. 6. Historical transaction volume of load aggregators

When the relevant data is substituted into the model shown in 4.2, the decision results after June are shown in Figure 3, and the specific data are shown in Table 3.

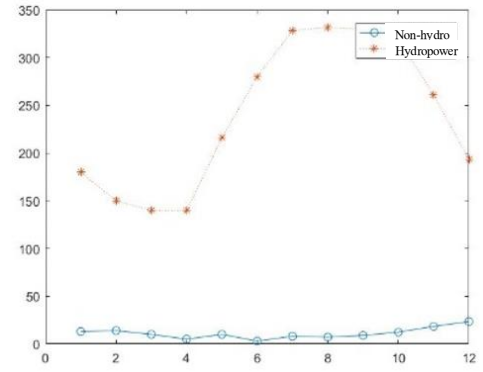

Fig. 7. Mid-month monthly power purchase decision results

In this case, it can be calculated that the minimum cost of purchasing electricity in the final year is 1.936 billion yuan. Compared with the minimum cost power purchase plan at the beginning of the year, the cost is increased at this time, but this is still the optimal power purchase plan under the current scenario.

\section{Conclusion}

This paper summarizes the purchase of electricity by load aggregators, and summarizes the considerations of supply and demand balance, quota assessment, electricity market conditions, and minimum electricity purchase costs. The main factors put forward the optimal power purchase decision at the beginning of the year and the rolling optimization model of the power purchase decision during the year, which can provide guidance for load aggregators to allocate and implement renewable energy quotas.

\section{Acknowledgements}

Supported by Research and development project of key technology of electric energy trading for electric power spot market and green energy trading.

\section{References}

1. L. Cheng, Y.X Wan,F. Zhang,et al. Automation of Electric Power Systems, Operation mode and control strategy of air conditioning service based on load aggregator business, $\mathbf{4 2 , 8}$ (2018)

2. Z.M Ma, H.W Zhong, Z.F Tan,et al. Automation of Electric Power Systems, Mechanism design of quota system to stimulate renewable energy demand and supply the country's renewable energy market,24,96(2017)

3. X. Zhang, Z. Chen, Z.M Ma, et al. Power System Technology, Research on the electricity market trading system adapted to the renewable energy quota system, 8(2019)

4. F.G Dong, L. Shi, Automation of Electric Power Systems,Design and simulation of renewable energy quota system and green certificate transaction mechanism,43,113 (2019)

5. X.L Chen, F. Lin, L.Y Wang, et al. Journal of Fuzhou University (Natural Science Edition). Research on Optimized Combination of Power Purchase of Electricity Sales Companies Considering Renewable Energy Quota System, 47,199 (2019) 